\title{
Spray Drying Technology of Karchikai (Momordica cymbalaria) Juice Powder
}

\author{
T. Veena*, Udaykumar Nidoni, G. Sudha Devi and Sharangoudar Hiregoudar
}

Department of Processing and Food Engineering, College of Agricultural Engineering, University of Agricultural Sciences, Raichur, Karnataka, India

*Corresponding author

\section{A B S T R A C T}

\section{Keywords}

Spray drying, Maltodextrin, Shelf life, Anti diabetic

Article Info

Accepted:

20 January 2021 Available Online: 10 February 2021
Momordica cymbalaria (M. cymbalaria) is one of the species of cucurbitaceae family. The plant is a perennial climber available only during the monsoon season and is found in the south Indian states of Andhra Pradesh, Karnataka, Madhya Pradesh, Maharastra, and Tamil Nadu. India is the second largest producer of vegetables in the world after china. As per ICMR recommendation vegetable consumption is $280 \mathrm{~g} /$ day, but the actual consumption of vegetable is only $135 \mathrm{~g} /$ day. This gap is due to load on production of conventional foods. To overcome this challenge, it is essential to explore the available underutilized vegetables. These underutilized vegetables are far superior in nutrition and have medicinal properties along with high crop yield potential. The crop is valued for its edible fruits, and leaves as vegetable and its tubers are mainly preferred for medicinal purpose. The beta-carotene content of karchikai was $224.9 \mathrm{Ig} / 100 \mathrm{~g}$ and that of sponge gourd and ridge gourd was 200I.U/100 $\mathrm{g}$ and $55 \mathrm{I} . \mathrm{U} / 100 \mathrm{~g}$ respectively. Karchikai contained a higher amount of ascorbicacid $160.77 \mathrm{mg} / 100 \mathrm{~g}$ on a fresh weight basis. The iron and phosphorous content of karchikai was also found to be higher (130.00 mg and $5.50 \mathrm{mg} / 100 \mathrm{~g}$, respectively) compared to other species. The nutrient contents of Fruits of the two vegetables M. cymbalaria (Karchikai) and Momordica charantia (Bittergourd) are compared. The calcium content of Karchikai is three times higher than that of the Bitter gourd. The higher concentration of this nutrient in Karchikai may be exploited and used. The ascorbic acid (Vitamin C) content of Karchikai is two times higher than that of Bitter gourd. The drying of foods in the open sun is a practice being followed in many countries since ancient times, especially by individual households and small scale enterprises. Drying is a part of many conventional food preparations. It also helps to impart special taste and store food items for longer periods. Spray drying technology has given major contribution in drying of liquid products and stores it for high shelf life. The karchikai juice was made into powder by using spray dryer. Maltodextrin was added as binding agent. The proximate analysis and physiological properties was carried out of all the samples.

\section{Introduction}

Momordica cymbalaria (M. cymbalaria) is one of the species of cucurbitaceae family. The plant is a perennial climber available only during the monsoon season and is found in the south Indian states of Andhra Pradesh, Karnataka, Madhya Pradesh, Maharastra, and Tamil Nadu. So far no review has been covered from the literature encompassing 
valuable attributes of $M$. cymbalaria in all dimensions. Its versatile utility as a nutritious vegetable, folk medicine and functional food ingredient provoked us to compile a comprehensive review of this multipurpose fruit on the distribution, nutritional attributes and phytochemicals composition and its medicinal properties.

Karchikai belongs to the family Cucurbitaceae and is commonly known as melons, gourds or cucurbits and includes crops like cucumbers, squashes (including pumpkins), luffas, melons (including watermelons). The family is predominantly distributed around the tropics, where those with edible fruits were amongst the earliest cultivated plants in both the old and new world. Momordica is one among the different genera of cucurbitacae which includes 47 species. This is one of the most genetically diverse groups of food plants in the plant kingdom. These are used as vegetables and also having high nutraceutical values. Production of cucurbits seems to have increased over the time due to high demand and consumer awareness on the health benefits of cucurbit fruits.

Fruits are the economic part of this crop. Fruits are green in color and these are used as vegetables. According to the studies conducted by various scientists the fruit of this plant has been reported to possess Hypoglycemic, Hypolipidemic, Cardio protective, Hepatoprotective (Koneri et al.2008), Nephroprotective (Kumar et al., 2011) and Anti diarrhoel properties. (Swamy et al., 2008). The presence of Saponinis the responsible for Hepato protective, Antioxidant and Anticancer Properties reported by Patel et al., (2014). Antimicrobial activity was also reported by Kulkarni et al., 1992. Fruits are also used in treating several disorders such as, rheumatism, sub acute cases of spleen and liver disease. The fruit juice is also used for the treatment of malaria, wounds, worms, and parasites. Rao et.al 2001 reported that fruits possess antidiabetic and hypoglycemic activity. It is also reported that alcoholic extract of fruits has significantly reduced the serum glucose level in both normal and type II diabetic rats (Kumar et.al 2010).

Momordica plant parts are characterized by a wide diversity of bioactive compounds such as phenolic acids, flavonoids, carotenoids cucurbitane triterpenoids, and phytosterol. The potential health benefits of phytochemical found in Momordica species have received ample attention in the recent literature, focusing especially on compounds with high antidiabetic, antitumor and antioxidant properties.

\section{Need of drying}

The drying of foods in the open sun is a practice being followed in many countries since ancient times, especially by individual households and small scale enterprises. Drying is a part of many conventional food preparations. It also helps to impart special taste and store food items for longer periods. One disadvantage of this conventional method of drying is that the products may be spoiled due to adverse weather conditions and also contaminated with dust, insects and excreta. Further, the process is time consuming, drying may not be uniform, and the area requirement is large.

Momordica cymbalaria (karchikai), is called as "under utilized crop", due to several reasons, first of all because it is very rarely available and it is seasonal crop which will be available only 3-4 months in a year. The lack of information on its nutritive value has resulted in making the karchikai, production uneconomical. Drying is the most important process to preserve the karchikai fruit, which 
increases its shelf life and makes it available throughout the year.

Karchikai is seasonal in nature, its availability is limited only to some part of the year. It is harvested at green, tender stage; hence it cannot be stored for longer period. In this connection, investigation was carried out to study the effect of drying characteristics of karchikai to make it available in off season under forced convection method.

\section{Materials and Methods}

The Momordica cymbalaria (Plate 1) were procured from the local market of Raichur, Karnataka. Juice was extracted from juicer and it is filtered using muslin cloth. The additives viz., maltodextrin other related chemicals were procured from M/s Himedia, Mumbai. All the chemicals used were of analytical grade.

\section{Spray drying}

The tall type spray dryer (Make: SM Scientech, Kolkata), a vertical co-current type with an evaporation rate of $1000 \mathrm{ml} . \mathrm{h}^{-1}$, was used in the present study. The components of spray dryer are air filter, air heater, air distributor, two fluid nozzles, drying chamber, collection glass bottles, cyclone separator and air compressor. Spray drying involved spraying the karchikai juice using two fluid nozzles at the pre-determined inlet air temperature and outlet air temperatures, feed pump rate and blower speed. Drying was carried out at three different inlet air temperatures viz., 140, 150 and $160{ }^{\circ} \mathrm{C}$ and at constant outlet air temperature of $80{ }^{\circ} \mathrm{C}$, with three different maltodextrin percentage viz., 20,30 and $40 \%$ with the fixed flow rate of 10 $\mathrm{ml} / \mathrm{min}$. The karchikai powder samples were collected from the cyclone (Plate 3). The samples were packed in PET pouches, Glass bottles and stored at room temperature.
The powders were analysed for proximate and functional properties. All the experiments were performed in triplicate.

\section{Karchikai powder determination of proximate and functional properties}

The karchikai juice powders were analyzed to determine the proximate composition viz., moisture content, water activity and functional properties viz., loose bulk density, tapped bulk density, dispersibility, solubility, Hausner Ratio (HR) and Carr's Index (CI) of karchikai juice powder were determined using standard procedures as explained below.

\section{Bulk density}

The bulk density of powder samples were measured according to the procedure described by Caparino et al., (2012) and Lebrun et al., (2012). Approximately, $1 \mathrm{~g}$ of powdered sample was freely poured into a 5 $\mathrm{ml}$ graduated glass cylinder (readable at $1 \mathrm{ml}$ ) without tapping and disturbance and this was measured as loose bulk density of sample. The same samples were repeatedly tapped for 20 times manually by lifting and dropping the measuring cylinder under its own weight at a vertical distance of $14 \pm 2 \mathrm{~mm}$ height over a rubber mat until negligible difference in volume between succeeding measurements was observed and this was measured as tapped bulk density of karchikai juice powder (Hari et al., 2013). The bulk density sample was computed by using the following formula;

Weight of powder (g) Bulk Loose bulk density $\left(\right.$ g.cc $\left.{ }^{-1}\right)=$

powdered volume (cc)

Weight of powder $(\mathrm{g})$
Tapped bulk density $\left(\mathrm{g} \cdot \mathrm{cc}^{-1}\right)=\frac{}{\text { Tapped powdered volume }(\mathrm{cc})}$ 


\section{Flow ability and cohesiveness of powder}

The powder samples were evaluated for their flow ability and cohesiveness in terms of Carr's Index (CI) and Hausner Ratio (HR), respectively. Both CI and HR were calculated from the loose bulk and tapped densities of the karchikai juice powder, according to formula given by Olayemi et al., (2008).

\section{Carr's index}

The compressibility index of the karchikai juice powder was determined by Carr's Index (Compressibility Index). It is a simple test to evaluate the Carr's Index from loose bulk density and tapped density of nanoencapsulated probiotic bitter gourd juice powder. The formula for Carr's Index is as below;

\footnotetext{
Tapped bulk density $\left(\mathrm{g} \cdot \mathrm{cc}^{-1}\right)-$ Loose bulk $\left(\mathrm{g} \cdot \mathrm{cc}^{-1}\right)$

Carr's Index $(\%)=\frac{}{\times 100}$

density Tapped bulk density (g.cc $\left.{ }^{-1}\right)$
}

\section{Hausner ratio}

The Hausner Ratio is a number that is correlated to the flow ability of a karchikai juice powder. It was calculated by using the following formula;

$$
\text { Hausner Ratio }=\frac{\text { Tapped bulk density }\left(\mathrm{g} \cdot \mathrm{cc}^{-1}\right)}{\text { Loose bulk density }\left(\mathrm{g} \cdot \mathrm{cc}^{-1}\right)}
$$

\section{Statistical analysis}

The experimental data obtained was statistically analyzed using statistical software, Design Expert Version 7.7.0 trial version (State-Ease, Minneapolis, MN). The models generated to represent the responses were evaluated in terms of $F$ ratio. The effects of the independent variables on the physical properties of the powders were studied. The statistical analysis was carried out using factorial completely randomized block design (FCRD).

\section{Results and Discussion}

The developed karchikai juice powder is as shown in Plate 3.

The physiological parameters of karchikai juice powders viz., moisture content, dispersibility, $\mathrm{pH}$, TS, solubility, water activity, Carr's Index, Hausner's ratio and bulk density were determined by standard methods was carried out thrice and the average values of proximate composition are presented in Table 1 below.

The karchikai juice powder produced with maltodextrin at lower inlet air temperature showed higher $(\mathrm{P}<0.05)$ moisture content than that produced with mixture of maltodextrin at the same inlet air temperatures (Table 1). These results are due to higher drying rate and decreased amount of water introduced to the drier (Masters, 1991; Perez-Munoz and Flores, 1997). The moisture content of powder ranged from 3.47 to $6.72 \%$ (d.b.) and water activity of the powder ranged from 0.2 to 0.27. The results of proximate compositions were in accordance with Patil et al., (2014) on spray drying of guava powder. The decreasing trend may be due to increasing drying temperature resulted in greater loss of water of resultant powder, due to the higher rate of heat transfer into particles, causing faster water removal. Increasing the total solids content in the feed solution prior to spray drying, reduced the total amount of water available for evaporation. T9 sample has given best results in significant way.

The loose bulk density of karchikai juice powder ranged from 0.34 to $0.39 \mathrm{~g} / \mathrm{cc}$ with an average of $0.38 \mathrm{~g} / \mathrm{cc}$. Increase in inlet air temperature decrease of bulk density due to skinning over or case-hardening of the droplets. Bulk density increased with increase in feed concentration it might be due to the 
decrease of occluded air content, it led to decrease in particle volume.

The CR and HR values of karchikai juice powder ranged from 18.16 to 21.32 with an average of 19.67 and HR values of karchikai juice powder ranged from 1.4 to 1.25 with an average of 1.19 . The CI and HR values were decreased with increase in inlet air temperature as well as concentrations it might due to the reduction of particle size as well as increase of surface area per unit mass of powder.

The dispersibility of karchikai juice powder ranged from 84.91 to $89.48 \%$ with an average of $86.16 \%$. Dispersibility decreased with increase in inlet air temperature due to low wettability, whereas increased with increase in concentration due to low air content (Fig. 1-6).

Table.1 Physiological parameters of Karchikai juice powder

\begin{tabular}{|r|r|l|l|l|r|l|l|r|r|}
\hline $\begin{array}{c}\text { M D } \\
\text { \% }\end{array}$ & $\begin{array}{c}\text { Tempera- } \\
\text { ture }\end{array}$ & & MC & $\begin{array}{l}\text { Dispers- } \\
\text { ibility }\end{array}$ & Solubility & aW & CI & HR & \multicolumn{1}{l|}{ BD } \\
\hline $\mathbf{2 0 \%}$ & 140 & T1 & 6.72 & 89.48 & 93.33 & 0.27 & 21.32 & 1.25 & 0.39 \\
\hline & 150 & T2 & 5.46 & 84.74 & 92.67 & 0.24 & 20.12 & 1.2 & 0.37 \\
\hline & 160 & T3 & 3.69 & 78.89 & 92.33 & 0.23 & 19.32 & 1.19 & 0.36 \\
\hline $\mathbf{3 0 \%}$ & 140 & T4 & 6.43 & 89.76 & 90.67 & 0.26 & 20.82 & 1.23 & 0.4 \\
\hline & 150 & T5 & 5.32 & 86.43 & 89.32 & 0.22 & 19.21 & 1.17 & 0.37 \\
\hline & 160 & T6 & 3.65 & 83.15 & 88.00 & 0.21 & 18.73 & 1.14 & 0.35 \\
\hline $\mathbf{4 0 \%}$ & 140 & T7 & 6.26 & 90.45 & 90.33 & 0.23 & 20.21 & 1.21 & 0.43 \\
\hline & 150 & T8 & 5.22 & 87.64 & 85.33 & 0.2 & 19.12 & 1.17 & 0.39 \\
\hline & 160 & T9 & 3.47 & 84.91 & 84.66 & 0.19 & 18.16 & 1.14 & 0.34 \\
\hline & Mean & & 5.13 & 86.16 & 89.62 & 0.22 & 19.67 & 1.19 & 0.38 \\
\hline & SD & & 0.19 & 3.16 & 3.28 & 0.02 & 0.72 & 0.04 & 0.014 \\
\hline & CV & & 3.70 & 3.66 & 3.66 & 3.11 & 3.65 & 1.19 & 3.69 \\
\hline
\end{tabular}

MD- Malto dextrin

Fig.1 The effect of spray drying on moisture content of Karchikai juice powder

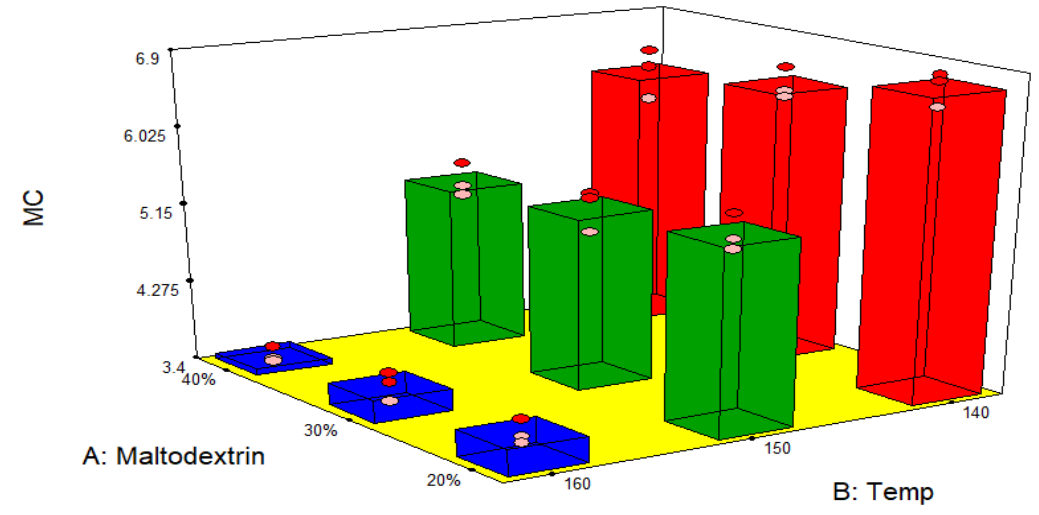


Fig.2 The effect of spray drying on loose bulk density of karchikai juice powder

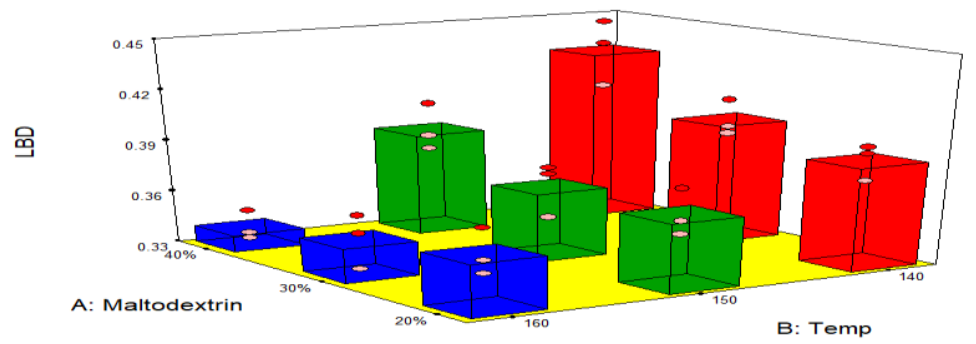

Fig.3 The effect of spray drying on CI of Karchikai Juice Powder

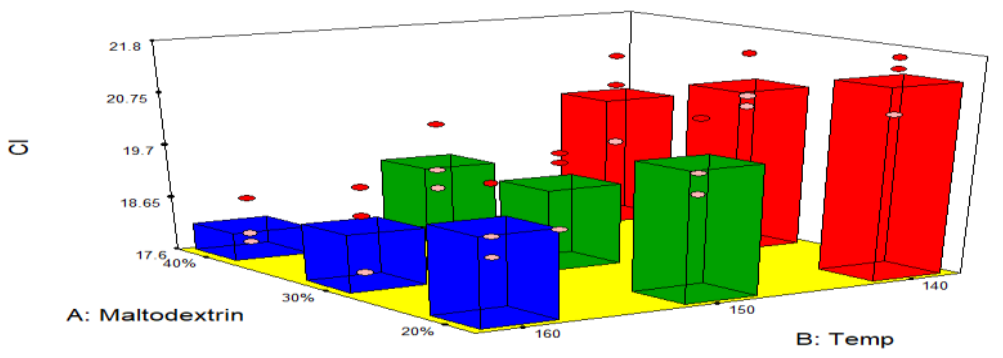

Fig.4 The effect of spray drying on HR of Karchikai Juice Powder

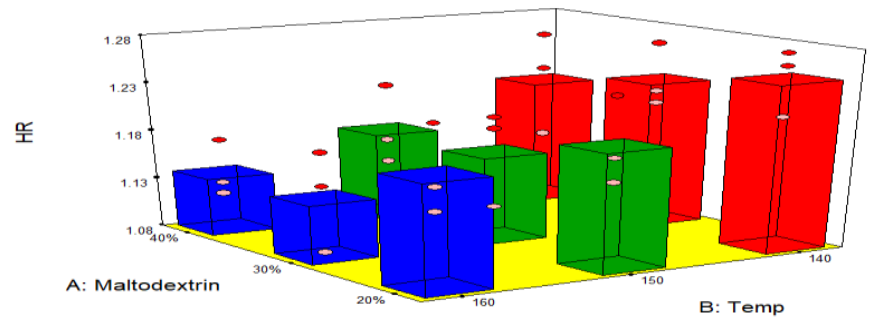

Fig.5 The effect of spray drying on Dispersibility of Karchikai Juice Powder

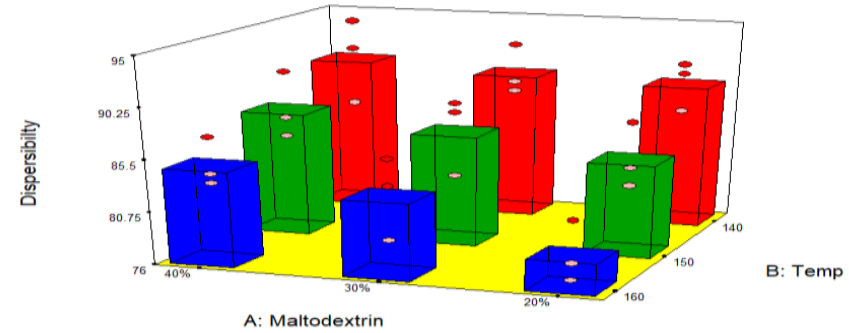


Fig.6 The effect of spray drying on solubility of Karchikai Juice Powder

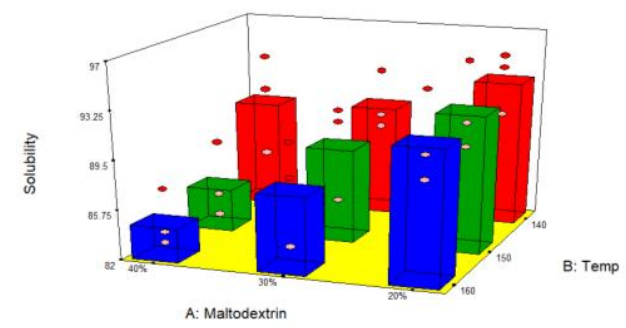

Plate.1 Fresh Karchikai and juice used for the experimentation

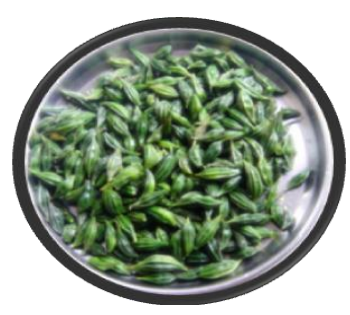

a) Fresh Karchikai

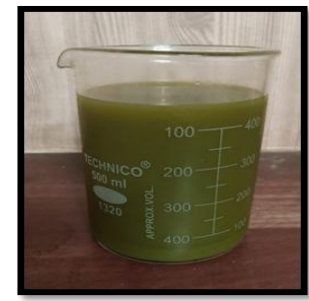

b) Karchikai Juice

Plate.2 Spray drier used for production of Karchikai powder

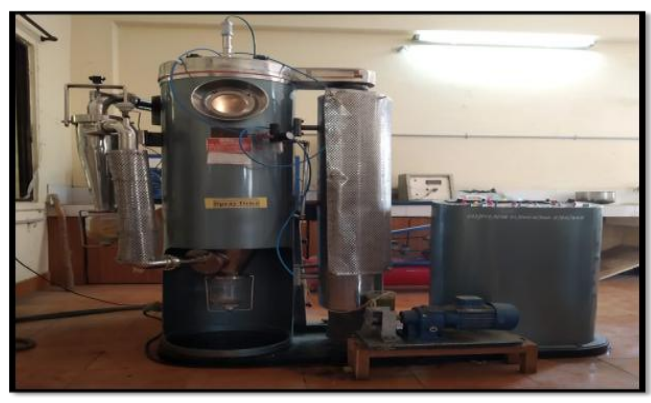

Plate.3 Karchikai juice powder

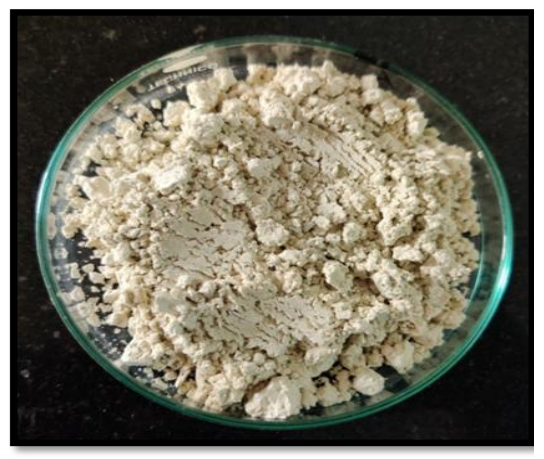




\section{Plate.4}

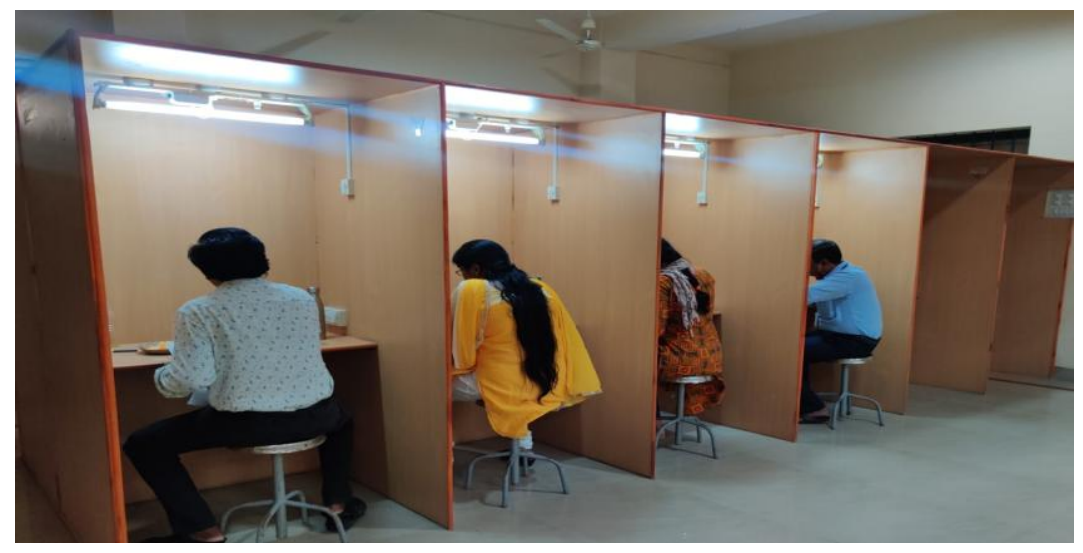

The solubility of karchikai juice powder ranged from 84.66 to $93.33 \%$ with an average of $89.62 \%$. Decrease of solubility with increase in inlet air temperature as well as concentration level it might be due to the denaturation of protein in the juice.

\section{Sensory evaluation of fresh karchikai juice and reconstituted karchikai juice}

Sensory characteristics of fresh and reconstituted juice prepared from karchikai juice powder. It can be identified from the plate 1 that the appearance of the fresh juice and reconstituted karchikai juice were different. All the samples recorded the good appearance score and qualitatively recorded as "like slightly". The colour of the fresh juice is higher than the reconstituted juices, among the reconstituted juices, the spray dried powder at inlet air temperature of $140^{\circ} \mathrm{C}$ with $20 \% \quad \mathrm{MD}$ concentration showed the best sensory value. Similarly, the sensory scores for flavour and overall acceptability were in moderately acceptable range.

In conclusion based on proximate analysis, functional properties and sensory evaluation, process technology for production of karchikai powder using spray drying at 20\% Malto dextrin concentration and inlet air temperature of $140{ }^{\circ} \mathrm{C}$ was optimized by the stastical model.

\section{References}

AOAC, (2005), Official Methods of Analysis. Eighteenth Edn., Assoc. Offl. Anal. Chem., Washington, DC.

Koneri R, Balaraman R, Saraswati CD. Antiovulatory and abortifacient potential of the ethanolic extract of roots of Momordica cymbalaria Fenzl.in rats. Indian J Pharmacol 2006; 38: 111-114.

Kulkarni, C. Y., BHARATI, P. AND PATIL, C. V., 1992. Antimicrobial activity of Luffa tuberosa (Roxb.). Indian Journal of Microbiology, 32(4): 493-495.

Patil, V., Chauhan, A. K. and Singh, S. P., (2014), Influence of spray drying technology on the physical and nutritional properties of guava powder. Intl. J. Curr. Microbiol. App. Sci., 3(9): 1224-1237.

Swamy V, Jayaveera KN, Bharti Reddy KR Antidiarrhoel acivity of fruit extract of Momordica cymbalaria. The internet $\mathbf{J}$ Nutrition and Wellness, 2008; 5(20): 1-9.

\section{How to cite this article:}

Veena, T., Udaykumar Nidoni, G. Sudha Devi and Sharangoudar Hiregoudar. 2021. Spray Drying Technology of Karchikai (Momordica cymbalaria) Juice Powder. Int.J.Curr.Microbiol.App.Sci. 10(02): 2384-2391. doi: https://doi.org/10.20546/ijcmas.2021.1002.283 